\title{
Green space study in 12 urban districts of Ha Noi using remote sensing data
}

\author{
Hai Khuong Van ${ }^{1 *}$, Trang Tran Huong ${ }^{2}$ \\ ${ }^{1}$ Water Resources Institute; khuongvanhai@gmail.com \\ ${ }^{2}$ Ha Noi University of Natural Resources and Environment; tranhuongtrang2608gmail.com \\ * Correspondence: khuongvanhai@gmail.com; Tel.: +84-974183835 \\ Received: 22 February 2021; Accepted: 15 April 2021; Published: 25 April 2021
}

\begin{abstract}
Today, the environmental situation in urban areas becoming polluted, people are increasingly interested in and want to live in green cities. This paper uses the satellite image Landsat 8 and the method of calculating the vegetation index (NDVI) combined with the multivariate regression analysis to study and evaluate the change of greenery area for the inner districts of Hanoi period 2013-2016. The study results show that the greenery area is strongly correlated in the central districts and the average correlation in districts with high urbanization or agricultural areas. The green tree density in Ha Noi city is quite different between the central districts and suburbs. In the suburb such as Long Bien, Ha Dong, Nam Tu Liem, North Tu Liem, Tay Ho, Hoang Mai the green tree density in the people is quite high, exceeding TCVN 9257:2012. To be specific, Long Bien district has the highest green tree density, with $134.2 \mathrm{~m} 2 /$ person up to 11 times national standards. Meanwhile, central districts such as Dong Da, Hai Ba Trung, Ba Dinh, Hoan Kiem, Thanh Xuan have very low green tree density, lower than the minimum standard of TCVN 9257: 2012. To be specific, Dong Da is the lowest green tree density with $2.5 \mathrm{~m}^{2}$ /person, lower than the TCVN 9257:2012 (>12 $\mathrm{m}^{2} /$ person) to 4.8 times national standards.
\end{abstract}

Keywords: NDIV; Green tree; Remote sensing; GIS; Ha Noi City.

\section{Introduction}

Urban inhabitants are expected to reach $70 \%$ of the world population by 2050 which is likely to lead to an array of environmental problems in cities such as increasing air pollution and climatic perturbations. Urban green spaces are defined as all natural, semi-natural, and artificial systems within, around and between urban areas of all spatial scales [1]. Urban green spaces promote multiple effects such as health, wellbeing and aesthetic benefits to urban dwellers [2]. Therefore, data on Urban green spaces are crucial to a range of issues in urban science such as planning, management and public health.

In the past decades, remote sensing technologies have occupied an important place in the study of Urban green spaces as they can generate repeated and complete coverage at different spatial scales and for different seasons [3]. Based on recent advances such as high spatial resolution imagery and free data access policies, remote sensing is providing a valuable set of tools which are able to minimize the need for field survey, even in highly heterogeneous and complex urban settings. For instance, remote sensing has proven to be effective for mapping street trees [4], detecting species within Urban green spaces [5], mapping invasive shrubs in Urban green spaces [6] and assessing vegetation health within Urban green spaces [7]. Furthermore, current remote sensing programs such as Copernicus [8] and Landsat not only provide historical timeseries data but also facilitate access to recently acquired data [9].

Green plants have a decisive role in Urban green spaces. They are considered as urban lungs, play a role in harmonizing the natural, human and social factors, improve the microclimate, the quality of living environment and create urban landscapes. Currently in Vietnamese cities, there 
VN J. Hydrometeorol. 2021, 7, 53-64; doi:10.36335/VNJHM.2021(7).53-64

are two methods of urban greenery management, including: land use map (used by departments). Stumps distribution map (used extensively in tree companies). Both methods of management have a common disadvantage that do not calculate the actual green plant cover.

Hanoi is a special urban area, is the brain center of politics-economy-culture of the country, has the highest urbanization rate in Vietnam [10-11]. The rapid urbanization rate has expanded the urban area, forming spontaneously developed residential areas with dense residential density, increasing construction density means vacant land is scarce, and Hanoi cabinet is increasingly "less" green. Therefore, the assessment of the current urban greenery in the city is very necessary to understand the current urban greening situation, as a tool for the State, the local government at all levels, and the people to work together to formulate policies. policies and implementation of measures to maintain and improve urban green coverage.

One of the most powerful tools to support green plant research is Remote sensing and GIS [12-14]. Remote sensing is one of the achievements of aerospace science and it is widely applied in many fields, from meteorology, hydrology, geology, environment, ...[15-17]. This paper uses remote sensing and GIS to study the urban green area fluctuation to assess the distribution and variation of urban green trees, support the management and planning of green plants in Ha Noi.

\section{Materials and methods}

\subsection{Data collection}

Using landsat 8 images with 30m resolution of United States Geological Survey (USGS) [18]. Additional Criterial tool is used to select $10 \%$ less cloud cover to ensure the best image, clear and cloudless in the study area. Information about Landsat 8 images collected and processed is given in Table 1.

Table 1. List statistics of Landsat 8 images were used in the study.

\begin{tabular}{ccccc}
\hline No. & Image code & Location & Date & Time (GMT +7) \\
\hline 1 & LC81270452013160LGN00 & $127 / 45$ & $09 / 06 / 2013$ & $10 \mathrm{~h} 25^{\prime}$ \\
2 & LC81270452013352LGN00 & $127 / 45$ & $18 / 12 / 2013$ & $10 \mathrm{~h} 24^{\prime}$ \\
3 & LC81270452014019LGN00 & $127 / 45$ & $19 / 01 / 2014$ & $10 \mathrm{~h} 24^{\prime}$ \\
4 & LC81270452015022LGN00 & $127 / 45$ & $22 / 01 / 2015$ & $10 \mathrm{~h} 23^{\prime}$ \\
5 & LC81270452015150LGN00 & $127 / 45$ & $30 / 05 / 2015$ & $10 \mathrm{~h} 22^{\prime}$ \\
6 & LC81270452015182LGN00 & $127 / 45$ & $01 / 07 / 2015$ & $10 \mathrm{~h} 22^{\prime}$ \\
7 & LC81270452015230LGN00 & $127 / 45$ & $18 / 08 / 2015$ & $10 \mathrm{~h} 23^{\prime}$ \\
8 & LC81270452016137LGN00 & $127 / 45$ & $16 / 05 / 2016$ & $10 \mathrm{~h} 22^{\prime}$ \\
9 & LC81270452016153LGN00 & $127 / 45$ & $01 / 06 / 2016$ & $10 \mathrm{~h} 23$ \\
10 & LC81270452016265LGN00 & $127 / 45$ & $21 / 09 / 2016$ & $10 \mathrm{~h} 23^{\prime}$ \\
11 & LC81270452016281LGN00 & $127 / 45$ & $07 / 10 / 2016$ & $10 \mathrm{~h} 23^{\prime}$ \\
12 & LC81270452016345LGN00 & $127 / 45$ & $10 / 12 / 2016$ & $10 \mathrm{~h} 23$, \\
\hline
\end{tabular}

Survey data was collected during the survey on $7^{\text {th }}$ January 2017 , which was used as a model for independent sampling. Survey sites are stable location, less variable locations of trees in the period from 2013 to 2016. Independent sites are randomly selected, but spread over the area. The number of survey sites are 45 points with 30 features for classification and 15 random points for checking the accurate classification. The map of the survey sites is shown in the Figure 1. 


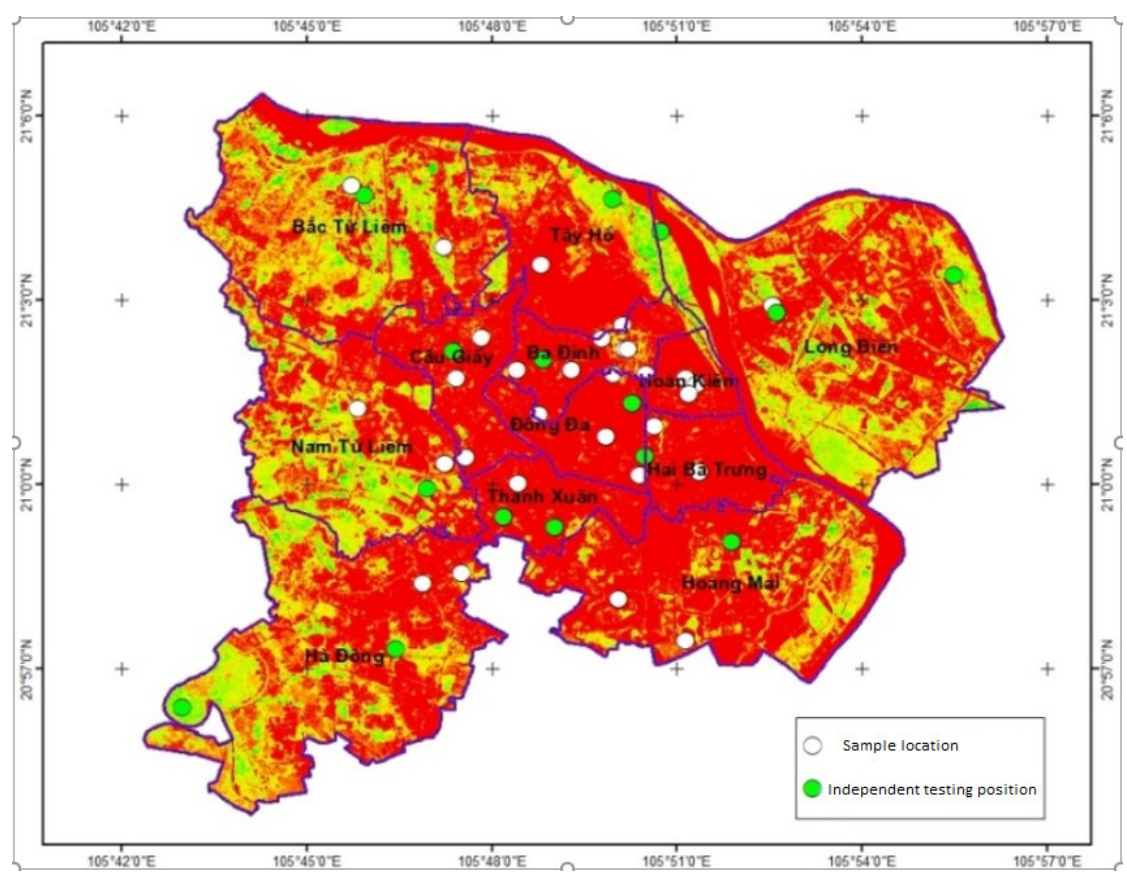

Figure 1. The survey locations in the research area.

\subsection{Methodology}

The steps of reseach and evaluation the variation of green plant area in the study include: 1) collecting satellite imagery data; 2) Filter and select images that are reliable; 3) Survey, identify the objects; 4) Calculate the NDVI vegetation index from the satellite images and compare with the sample from the survey; 5) Verification of NDVI index from independent samples; 6) Development of green plant distribution maps based on NDVI; 7) Evaluate the variation of tree area by multivariate regression. The method details of the steps are presented in Figure 2.

\subsubsection{The normalized difference vegetation index (NDVI)}

The normalized difference vegetation index (NDVI) is widely used to determine the distribution of vegetation, assess the growth and development crops, as a basis for forecasting drought, yield and product. The vegetation index is determined based on the different reflexes of the object between the visible and near infrared.

$$
N D V I=\frac{\mathrm{IR}-\mathrm{R}}{\mathrm{IR}+\mathrm{R}}
$$

where $\mathrm{R}$ is the reflection value of near infrared (NIR); $\mathrm{R}$ is the reflection value of the red wave length.

\subsubsection{Multivariate Linear Regression}

The development of plants associated with four weather conditions in the year. Therefore, the change of vegetation layer is often associated with the characteristics of climate such as rainfall, temperature, and humidity .... In the study, the authors have pointed out the relationship between NDVI and climatic factors that affect the density of green trees in urban areas [19-21].

The authors observed that the variation of vegetation area was strongly correlated with three climatic factors including temperature, humidity and rainfall. The general linear regression equation with three independent variables is of the form:

$$
Y=b_{0}+b_{1} \times X_{1}+b_{2} \times X_{2}+b_{3} \times X_{3}
$$

where $\mathrm{Y}$ is the dependent variable (variable plant area); $\mathrm{X}_{1}, \mathrm{X}_{2}, \mathrm{X}_{3}$ are independent variables (climate variables); $b_{0}$ is the original pitch; $b_{1}$ is the slope coefficient of $Y$ following by $\mathrm{X} 1$ while 
VN J. Hydrometeorol. 2021, 7, 53-64; doi:10.36335/VNJHM.2021(7).53-64

keeping $X_{2}, X_{3}$ constant; $b_{2}$ is the slope coefficient of $Y$ following by $X_{2}$ while keeping $X_{1}, X_{3}$ constant; $b_{3}$ is the slope coefficient of $Y$ following by $X_{3}$ while keeping $X_{1}, X_{1}$ constant.

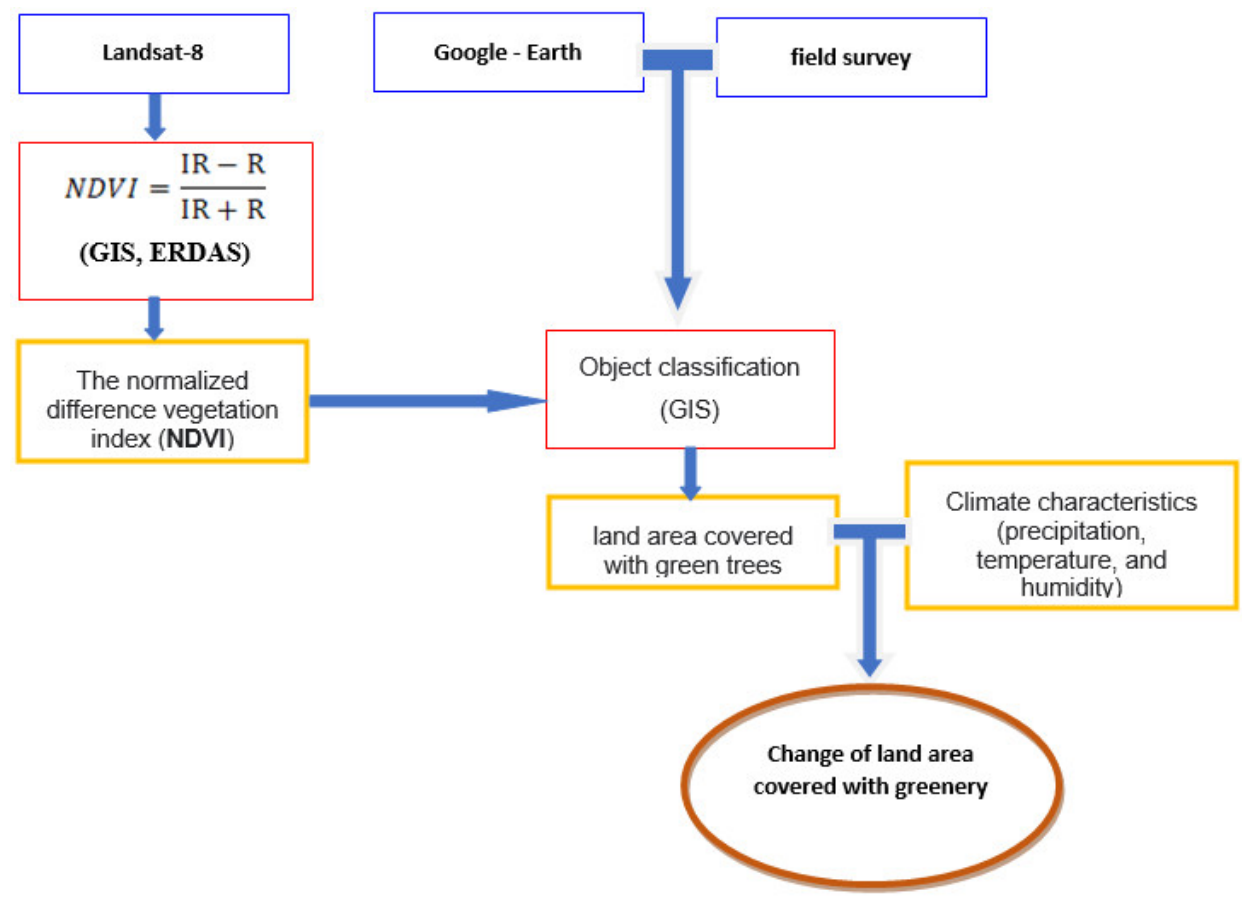

Figure 2. Overview diagram describing the steps taken.

\section{Results and disscusion}

The NDVI method is used to evaluate the plant index from satellite imagery. Initial results from satellite images show that NDVI in the inner of Ha Noi ranged from 0 to 0.48 (Figure 3).

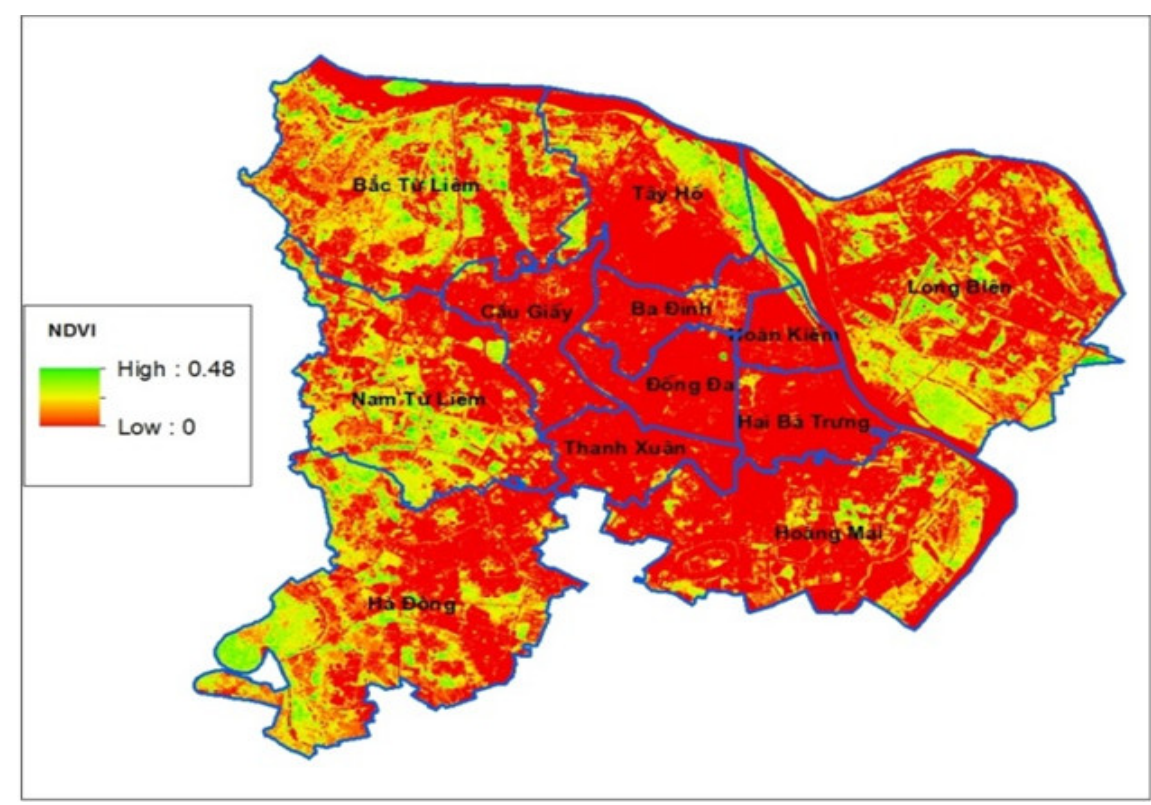

Figure 3. NDVI for the inner city on Octorber 7, 2016.

In order to eliminate non-vegetative sites, the initial NDVI results did not evaluate, 30 survey sites with 16 sites of the vegetation class, 5 points of the water surface, 2 points traffic class and 7 points in residential, commercial areas that has been used to accurate vegetation classification. Figure 4 shows the results of vegetation classification of some survey sites. The results of the calibration show that areas with a NDVI value of $\geq 0.18$ are vegetation cover, whereas areas with a NDVI value $<0.18$ are non-plants: traffic; water surface; residential areas; commercial center. The NDVI in this area is set to 0. 

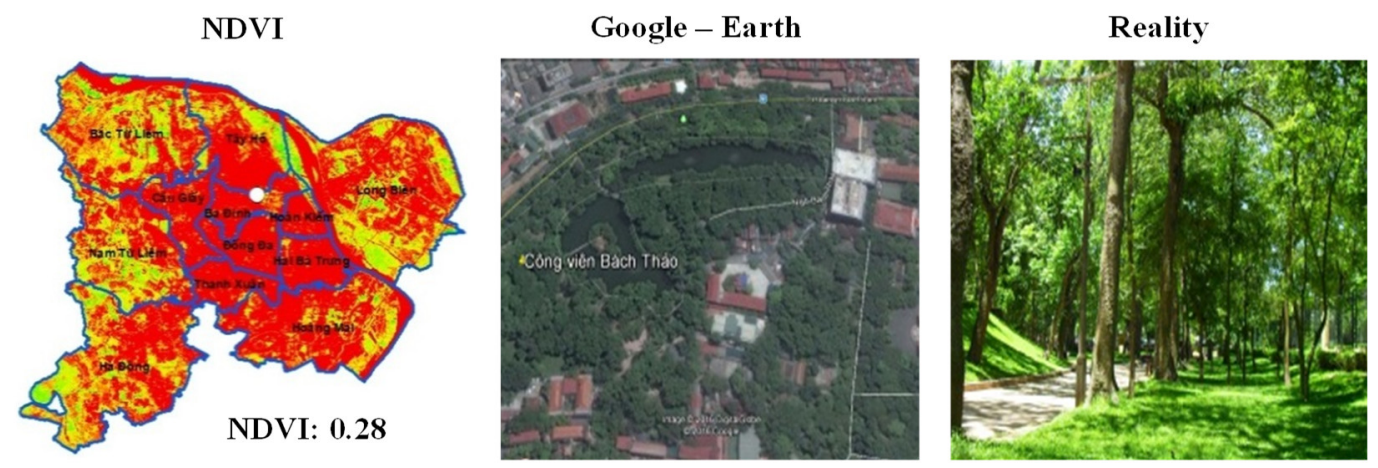

Bach Thao Park (105'49'48”E - 21'2'23"N)
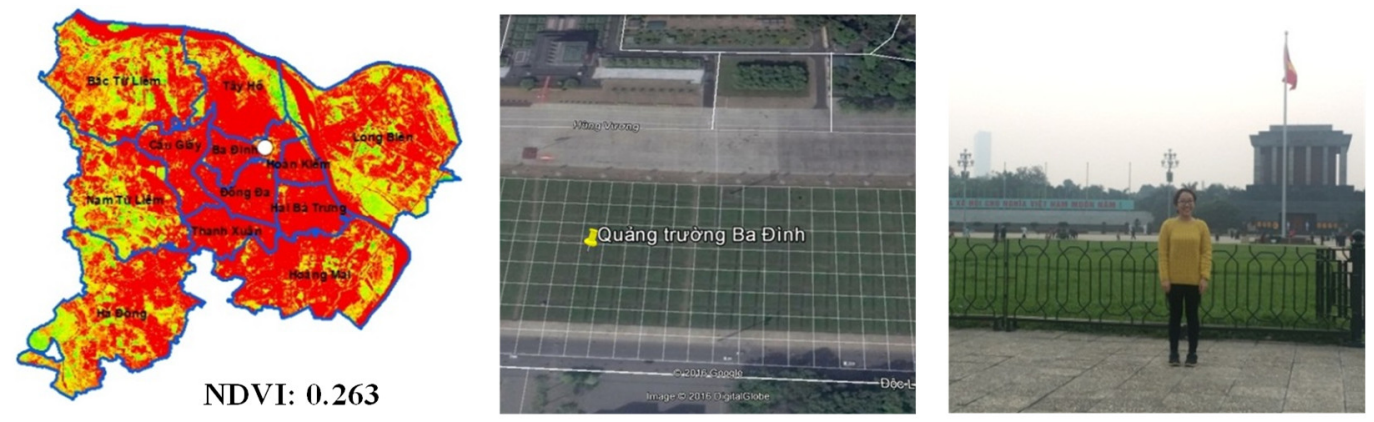

Ba Dinh Square (105050'9"E - 21 '2'13"N)
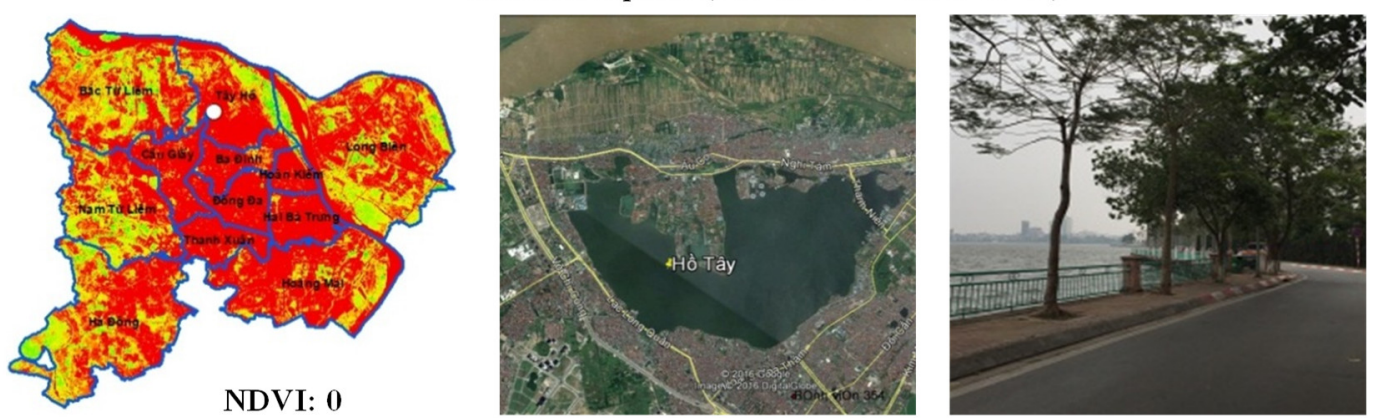

Nguyen Dinh Thi stress $\left(105^{\circ} 48^{\prime} 46^{\prime \prime} \mathrm{E}-21^{\circ} 3^{\prime} 35^{\prime \prime} \mathrm{N}\right)$

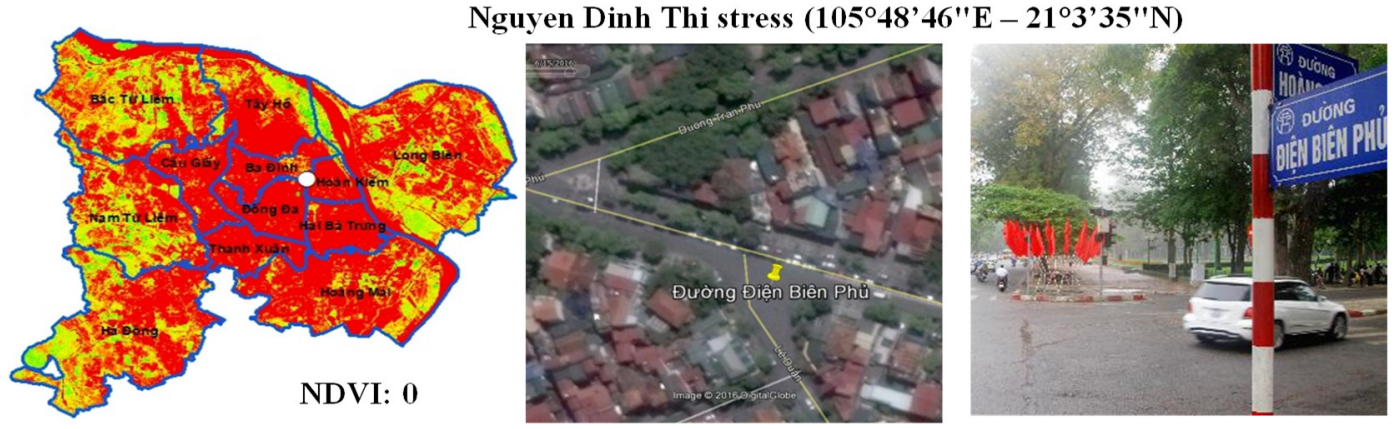

Dien Bien Phu stress (105 50 '31 'E - 21 $\left.{ }^{\circ}{ }^{\prime} 48^{\prime \prime} \mathrm{N}\right)$

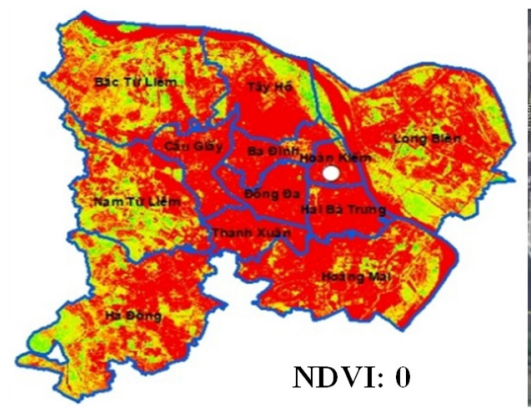

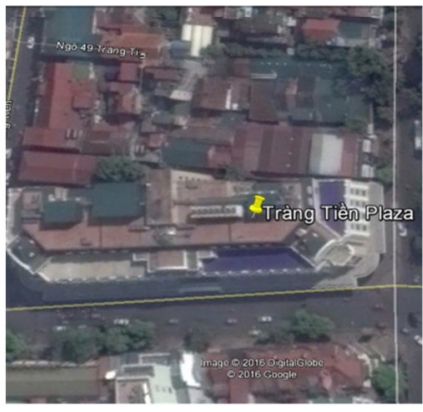

10-10-2016

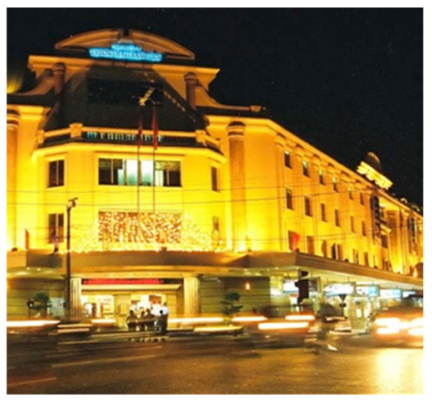

7-1-2017

Trang Tien Plaza $\left(105^{\circ} 51^{\prime} 10^{\prime \prime} \mathrm{E}-21^{\circ} 1^{\prime} 28^{\prime \prime} \mathrm{N}\right)$

Figure 4. Results of vegetation classification at some survey sites. 
NDVI

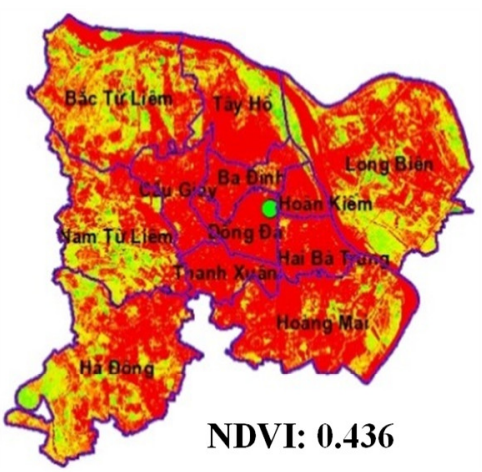

Google Earth

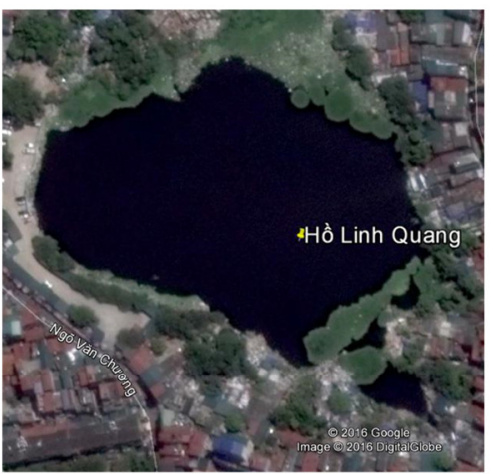

Reality

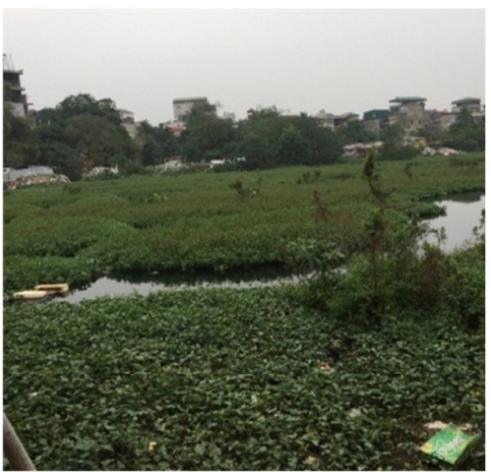

Linh Quang lake, Dong Da district (105 $\left.50^{\prime} 16^{\prime \prime} \mathrm{E}-21^{\circ} 1^{\prime} 19^{\prime \prime} \mathrm{N}\right)$
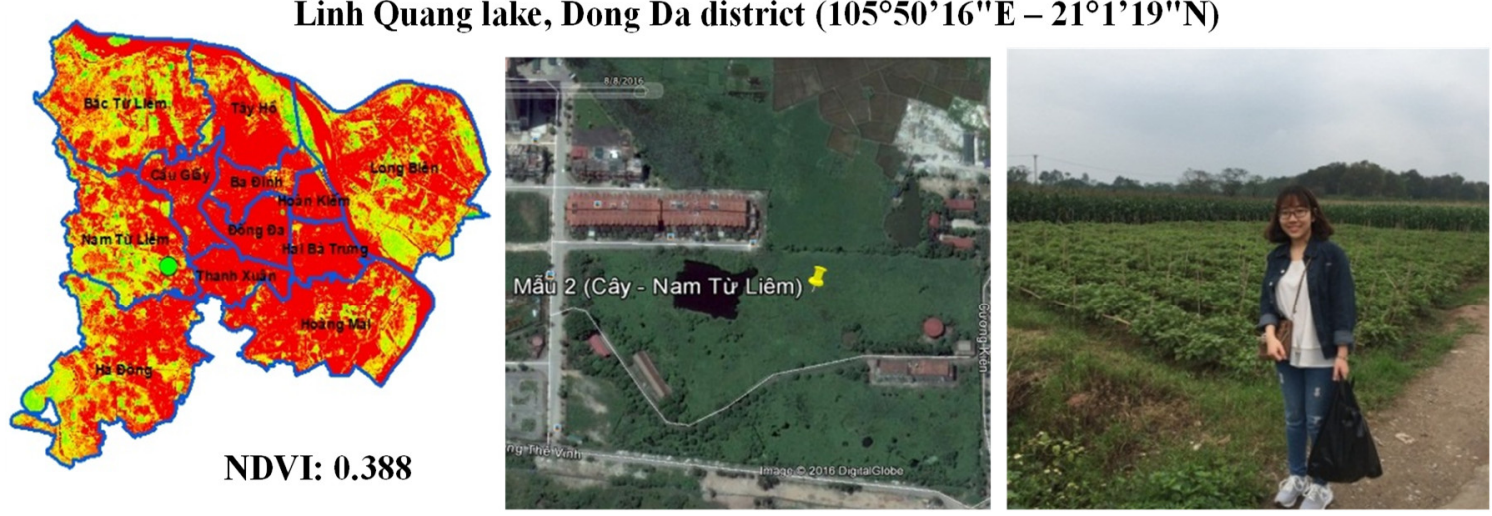

Corn field, Nam Tu Liem district $\left(10^{\circ} 46^{\prime} 58\right.$ "E - 20 $\left.{ }^{\circ} 59^{\prime} 56 " \mathrm{~N}\right)$

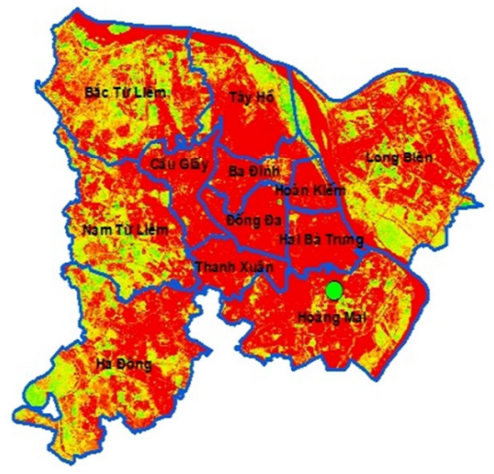

NDVI: 0

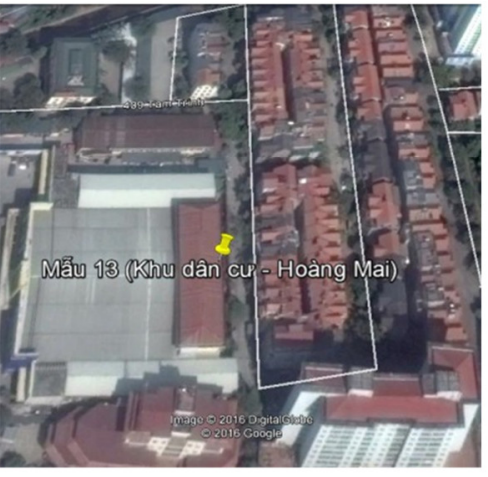

10-10-2016

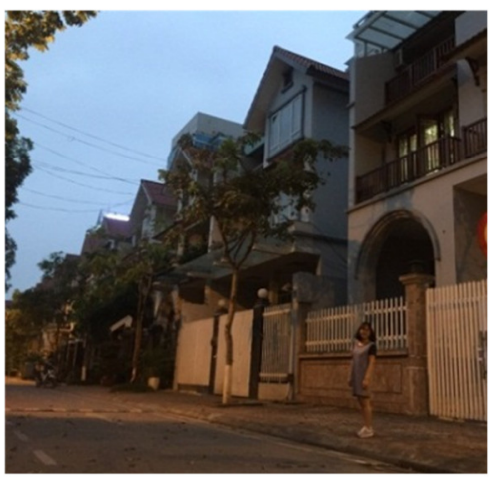

7-1-2017

Villa at Tam Trinh stress $\left(105^{\circ} 51{ }^{\prime} 54 \prime \mathrm{E}-20^{\circ} 59^{\prime} 4 ” \mathrm{~N}\right)$

Figure 5. Results of vegetation classification at some survey sites.

To exmamine the accuracy of vegetation classification, 15 independent survey sites were used to re-define the NDVI index including 8 sites vegetation class, 1 sites water, 4 sites traffic and 2 sites in the residential areas. The results shown that NDVI values at all sites are highly reliable. Especially, at Linh Quang Lake (Dong Da District), the NDVI was approximately 0.44 although under the plan, this is the water surface. In fact, the surface of Linh Quang Lake has been covered by duckweed and thick moss so the vegetation index calculated from high index satellite images is reasonable (Figure 5).

The calibrated and validated NDVI indexes are used to establish the vegetation distribution map in the inner city of Ha Noi from 12 satellite images for 12 different periods from 2013 to 2016. The results show that the green trees' areas in the inner of Ha Noi ranges from 148.8 to $160.7 \mathrm{~km}^{2}$. On December 2013, there is the lowest green areas, on June 2016, there is the largest green area (Error! Not a valid bookmark self-reference.). High green areas are concentrated in the summer months, 
VN J. Hydrometeorol. 2021, 7, 53-64; doi:10.36335/VNJHM.2021(7).53-64

from May to September, while the green areas are lower in the winter months (from October to January).

Table 2. Green trees area $\left(\mathrm{km}^{2}\right)$ in the inner city according to satellite image interpretation.

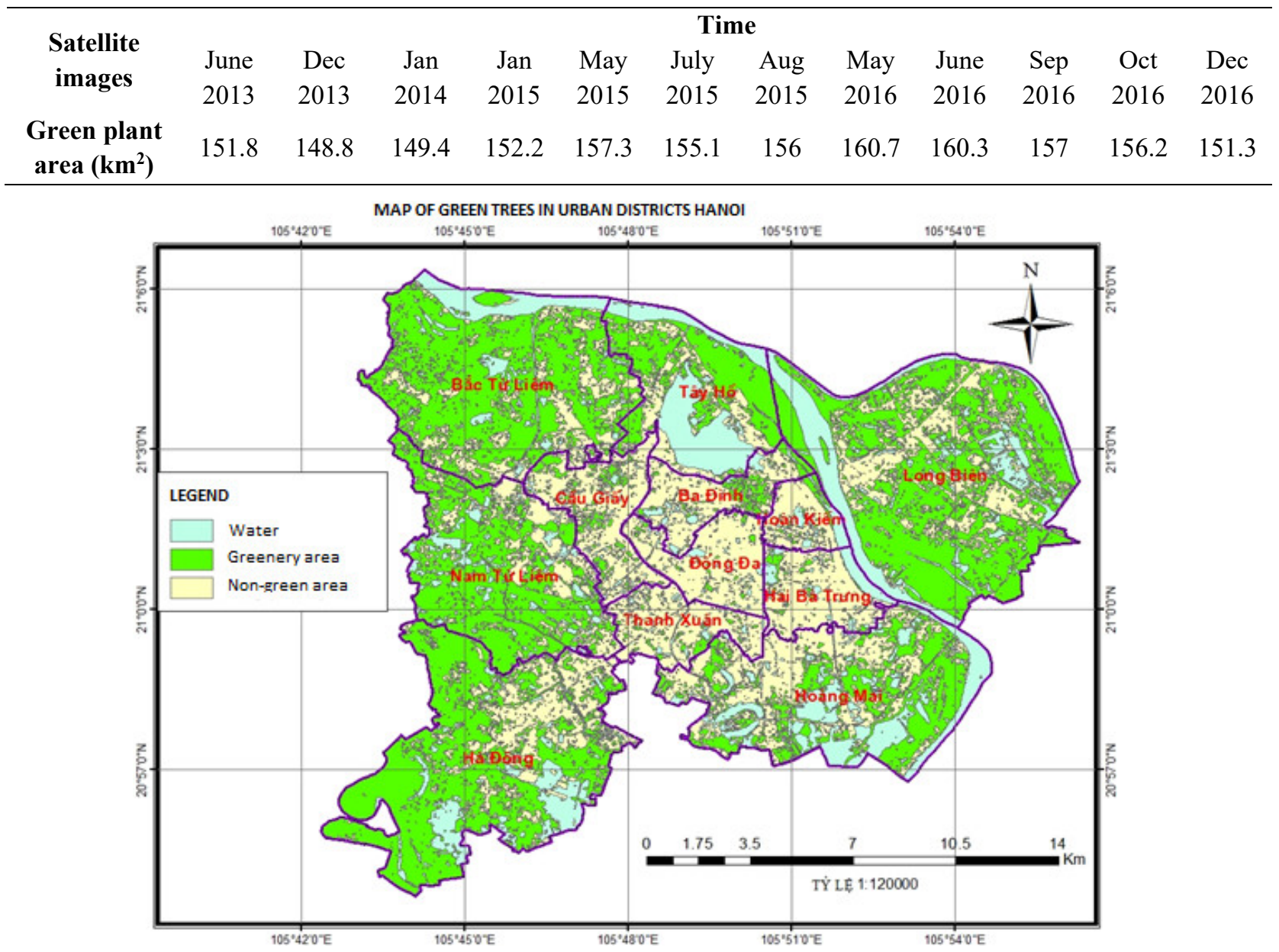

Figure 6. Vegetation distribution map in the inner of Ha Noi, on December 2016.

Because of the small number of satellite images, it does not reflect the changes of trees in time in Ha Noi. In order to restore the green area of the missing months, the multiple correlation function was constructed based on green plants area data that interpreted from satellite images and climatic factors such as monthly average temperature, average monthly humidity, total rainfall of studied area (Ha Dong station) at corresponding times (Table 3).

Table 3. Data were used to construct the linear regression equation for the correlation between green building area and climatic factors.

\begin{tabular}{ccccc}
\hline Time & $\begin{array}{c}\text { Green plant area } \\
\text { interpreted from } \\
\text { satellite imagaes }\end{array}$ & $\begin{array}{c}\text { Monthly average } \\
\text { temperature }\left({ }^{\circ} \mathbf{C}\right)\end{array}$ & $\begin{array}{c}\text { Average monthly } \\
\text { humidity }(\%)\end{array}$ & Total rainfall (mm) \\
\hline $6 / 2013$ & 151.8 & 29.4 & 78 & 237 \\
$12 / 2013$ & 148.8 & 15.5 & 75 & 28 \\
$1 / 2014$ & 149.4 & 17.0 & 77 & 3 \\
$1 / 2015$ & 152.2 & 17.7 & 81 & 30 \\
$5 / 2015$ & 157.3 & 30.0 & 80 & 95 \\
$7 / 2015$ & 155.1 & 29.7 & 77 & 287 \\
$8 / 2015$ & 156.0 & 29.5 & 81 & 412 \\
$5 / 2016$ & 160.7 & 28.4 & 80 & 74 \\
$6 / 2016$ & 160.3 & 30.9 & 75 & 28
\end{tabular}




\begin{tabular}{ccccc}
\hline Time & $\begin{array}{c}\text { Green plant area } \\
\text { interpreted from } \\
\text { satellite imagaes }\end{array}$ & $\begin{array}{c}\text { Monthly average } \\
\text { temperature }\left({ }^{\circ} \mathbf{C}\right)\end{array}$ & $\begin{array}{c}\text { Average monthly } \\
\text { humidity (\%) }\end{array}$ & Total rainfall (mm) \\
\hline $9 / 2016$ & 157.0 & 28.7 & 79 & 119 \\
$10 / 2016$ & 156.2 & 27.5 & 74 & 40 \\
$12 / 2016$ & 151.3 & 20.8 & 72 & 7 \\
\hline
\end{tabular}

The multiple correlation represents the relationship between the area of green tree and the average monthly rainfall, monthly humidity and total monthly rainfall in Ha Noi:

$$
\mathrm{GA}=135.09+0.5 \mathrm{~T}+0.085 \mathrm{H}+0.002 \mathrm{R}
$$

\subsection{Restoration green tree area in the inner of $\mathrm{Ha} \mathrm{Noi}$}

Using multiple correlation, the total area of green trees in the inner city from 2013 to 2016 has been restored. Research results show that green areas increase in rainy months and decrease in autumn and winter months. In addition, green areas in the inner city from 2013 to 2016 are quite stable and tend to increase slightly from 153.90 to 155.15 (Table 4, Figure 7).

Table 4. Green tree area in the inner of Ha Noi by the time.

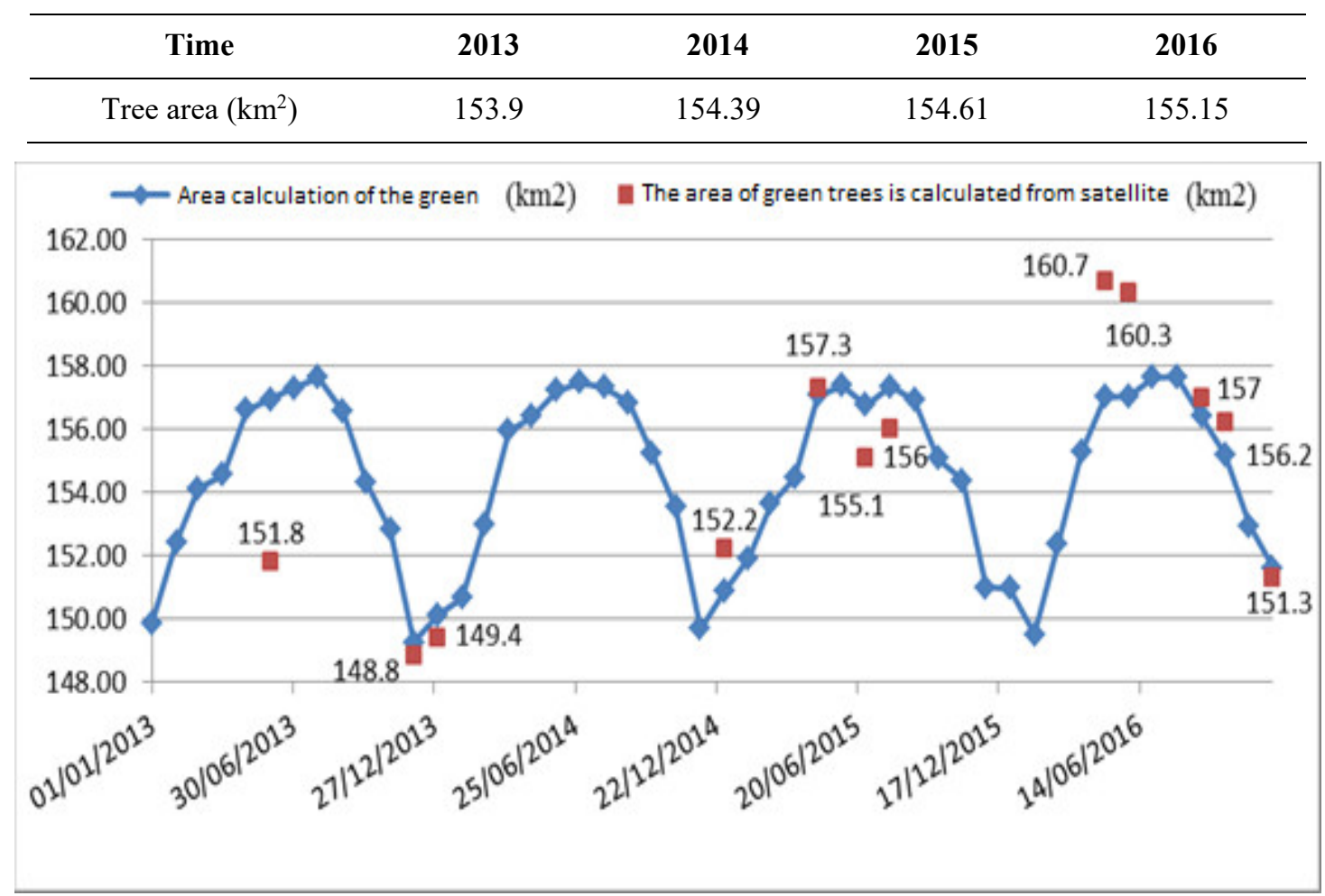

Figure 7. Green trees area in the inner city of Ha Noi in the period between 2013 and 2016.

Use the population data from the general statistics office to estimate the annual average of green trees in the inner city according to TCVN 9257: 2012. The results show that the inner city has a high density of trees per capita though it tends to decrease from 2013 to 2016 but compared with TCVN 9257: 2012 still exceeds 3 times. Although the green trees area in this period tends to increase slightly, however, given the urban population of Ha Noi increases rapidly $(5.5 \%$ from 2013 to 2016), the density of trees per capita tends to decrease (Table 5).

Table 5. The green trees dessity in the inner of Ha Noi.

\begin{tabular}{ccccc}
\hline Time & $\begin{array}{c}\text { Green tree area } \\
\left(\mathbf{k m}^{\mathbf{2}}\right)\end{array}$ & $\begin{array}{c}\text { Population } \\
(\text { million people) }\end{array}$ & $\begin{array}{c}\text { The density of trees } \\
\left(\mathbf{m}^{\mathbf{2}} / \mathbf{p e r s o n}\right)\end{array}$ & $\begin{array}{c}\text { TCVN } \\
\mathbf{9 2 5 7 : 2 0 1 2}\end{array}$ \\
\hline 2013 & 153.90 & 3089.20 & 49.80 & $12-15$
\end{tabular}


VN J. Hydrometeorol. 2021, 7, 53-64; doi:10.36335/VNJHM.2021(7).53-64 61

\begin{tabular}{ccccc}
\hline Time & $\begin{array}{c}\text { Green tree area } \\
\left(\mathbf{k m}^{\mathbf{2}}\right)\end{array}$ & $\begin{array}{c}\text { Population } \\
(\text { million people })\end{array}$ & $\begin{array}{c}\text { The density of trees } \\
\left(\mathbf{m}^{\mathbf{2}} / \text { person) }\right.\end{array}$ & $\begin{array}{c}\text { TCVN } \\
\mathbf{9 2 5 7 : 2 0 1 2}\end{array}$ \\
\hline 2014 & 154.39 & 3156.00 & 48.90 & $\left(\mathrm{~m}^{2} /\right.$ person $)$ \\
2015 & 154.61 & 3241.50 & 47.70 & \\
2016 & 155.15 & 3259.90 & 47.60 \\
\hline
\end{tabular}

\subsection{Restoration of green tree areas in the inner of $\mathrm{Ha}$ Noi}

Restoration of green tree areas in each district is carried out similarly to the inner city. Table 6 shows the reliability of the relationships between green plant areas each district and climatic factors.

Table 6. Evaluation the correlation between variables.

\begin{tabular}{ccc}
\hline District & The correlation coefficient (R) & Evalution \\
\hline Hoang Mai & 0.81 & \\
Tay Ho & 0.79 & \\
Hoan Kiem & 0.77 & Close correlation \\
Hai Ba Trung & 0.74 & \\
Dong Da & 0.72 & \\
Ba Dinh & 0,71 & \\
Thanh Xuan & 0.68 & \\
Cau Giay & 0.67 & \\
Nam Tu Liem & 0.65 & Quite close correlation \\
Bac Tu Liem & 0.55 & \\
Long Bien & 0.31 & \\
Ha Dong & 0.30 & \\
\hline
\end{tabular}

The linear regression equation was divided 12 districts in Ha Noi based on the correlation coefficient: the close correlation, the quite close correlation coefficient and the average correlation. Consequently, given the close correlation and quite close correlation, it is possible to use green tree area data in combination with interpreted area data to calculate the average green tree area in the period between 2013 and 2016. The pronvinces in the average correlation will use the green tree area interpreted from Landsat 8 to calculate the average green tree area in the period from 2013 to 2016.

Table 7. Green tree area in each district over the years.

\begin{tabular}{cccccc}
\hline Time & \multicolumn{5}{c}{ Green tree area $\left.\mathbf{( k m}^{2}\right)$} \\
\cline { 2 - 5 } District & $\mathbf{2 0 1 3}$ & $\mathbf{2 0 1 4}$ & $\mathbf{2 0 1 5}$ & $\mathbf{2 0 1 6}$ & $\mathbf{2 0 1 3 - 2 0 1 6}$ \\
\hline Hoang Mai & 16.97 & 16.87 & 16.9 & 16.96 & 16.93 \\
Tay Ho & 9.17 & 9.16 & 9.35 & 9.5 & 9.29 \\
Hoan Kiem & 0.83 & 0.79 & 0.83 & 0.94 & 0.85 \\
Hai Ba Trung & 0.97 & 0.95 & 0.92 & 1.18 & 1.00 \\
Dong Da & 0.94 & 0.88 & 0.9 & 1.02 & 0.94 \\
Ba Dinh & 2.5 & 2.49 & 2.58 & 2.66 & 2.56 \\
Thanh Xuan & 1.56 & 1.48 & 1.47 & 1.42 & 1.48 \\
Cau Giay & 2.6 & 2.54 & 2.65 & 2.58 & 2.59 \\
Nam Tu Liem & 22.62 & 22.8 & 22.75 & 21.89 & 22.52 \\
Bac Tu Liem & 29.73 & 29.74 & 29.69 & 29.67 & 29.71 \\
Long Bien & 33 & 34.58 & 33.65 & 36.28 & 34.38
\end{tabular}




\subsection{Assessment of green tree density according to TCVN 9257:2012}

The article assesses the green trees destiny in the inner city in 2016 based on the general statistics in 2016.

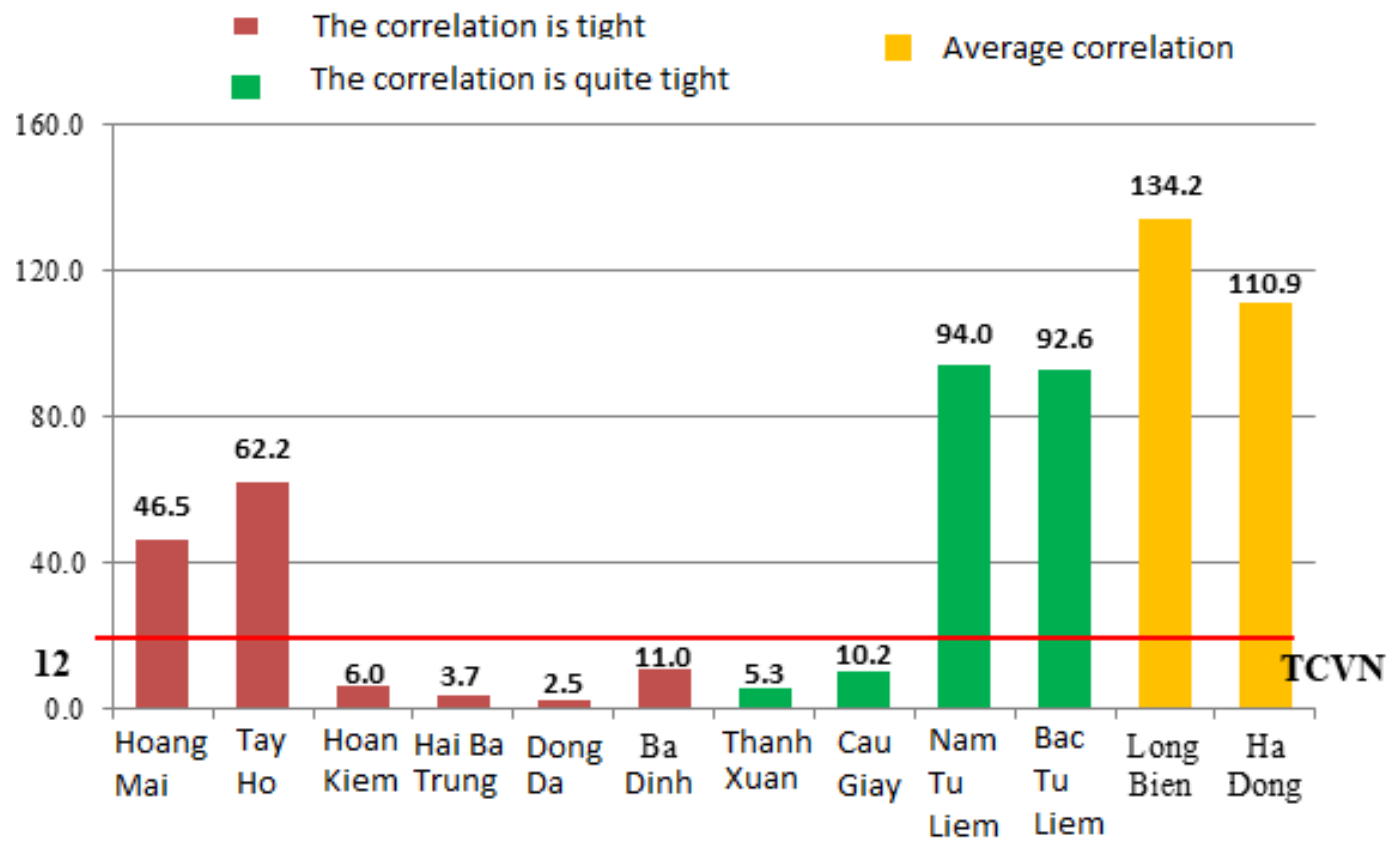

Figure 8. The green tree density in the inner of Ha Noi.

According to Table 7, the green tree density in the inner city are quite different between the central districts and suburbs. In the suburb such as Long Bien, Ha Dong, Nam Tu Liem, North Tu Liem, Tay Ho, Hoang Mai the green tree density in the people is quite high, exceeding TCVN 9257:2012. To be specific, Long Bien district has the highest the green tree density, with 134.2 $\mathrm{m}^{2} /$ person up to 11 times, followed by Ha Dong (110.9 m2/person), Nam Tu Liem ( $94 \mathrm{~m}^{2} /$ person), Bac Tu Liem (92.6 m²/person), Tay Ho (62.2 $\mathrm{m}^{2} /$ person) and Hoang Mai (46.5 m²/person).

Meanwhile, central districts such as Dong Da, Hai Ba Trung, Ba Dinh, Hoan Kiem, Thanh Xuan have very low the green tree density, lower than the minimum standard of TCVN 9257: 2012. To be specific, Dong Da is the lowest green tree density with $2.5 \mathrm{~m}^{2} /$ person, lower than the TCVN 9257:2012 (>12 m²/person) to 4.8 times. Followed by Hai Ba Trung district, the green tree destiny is $3.7 \mathrm{~m}^{2} /$ person, lower than the standard allowed more than 3 times. Hoan Kiem and Thanh Xuan have the green tree density at $5.3-6 \mathrm{~m}^{2} /$ person, lower than the permitted standard 2 times. Cau Giay and Ba Dinh have a density of $10.2 \mathrm{~m}^{2} /$ person and $11 \mathrm{~m}^{2} /$ person, respectively, reaching the minimum level of TCVN 9257:2012.

The explanation for the high green tree density in the suburbs that the population is not as crowded as in the central districts, the vacant land area is relatively large. Morever, the stuburbs concentrate many parks and large gardens of the city. For instance, Yen So park (Hoang Mai) is the largest urban park in Viet Nam - the largest green park of Ha Noi with total area 323 ha There are several parks and flower gardens, such as Yen So Park (Hoang Mai District), Viet Nam's largest urban park, the largest green park in Ha Noi with a total area of 323 hectares. In which, the park and lake area is 280 ha. Hoa Binh Park (BacTu Liem district) is the most modern park in the capital with an area of 20 ha; Ho Tay Flower Valley (Tay Ho provice) has an area of about 7,000 $\mathrm{m}^{2}$, and includes many different types of flowers; Nhat Tan flower garden, Hong river rocks (Tay Ho district), etc.

In the contract, the central districts where the population lives and are crowded. Especially, Dong Da district is the region with the largest population with 401,700 people (the population density of Dong Da is 40.331 person $/ \mathrm{km} 2$ ). Notably in the central district, $100 \%$ of the total area 
VN J. Hydrometeorol. 2021, 7, 53-64; doi:10.36335/VNJHM.2021(7).53-64

in natural land is non-agricultural land. Moreover, these are place which develop rapidly of infrastructure, agencies, schools, hospitals, monuments, landscapes... so people tend to live these areas. The empty lands are converted used purpose, the house was cleared, the trees were cut to the "century" works: entertainment complex, commercial center, shopping, apartment ... Given the dizzying development of the apartment building is the rapidly shrinking of green tree area. These are the reasons for the green plant density in these districts which is much lower than TCVN 9257:2012.

\section{Conclusions}

Remote sensing and GIS combined with multivariate regression in the study of urban green tree changes in the inner of Ha Noi show advantages to traditional methods. The results show that the area of green trees in the inner of Ha Noi is quite stable and tends to increase slightly at $0.8 \%$ in the period from 2013 to 2016. The average greenback annual average from 2013 to 2016 is $50.8 \%$. Plant density per capita has fallen from $49.8 \mathrm{~m}^{2} /$ person (2013) to $47.6 \mathrm{~m}^{2} /$ person (2016) compared with TCVN 9257:2012 still exceeds 3 times. The main cause of the decline is the urbanization of districts and the urban population of Ha Noi on the increase of about $5.5 \%$ from 2013 to 2016. The density of green tree per capita in the inner of Ha Noi is three times larger than Viet Nam standards.

The green tree destiny is clearly divided among urban and suburban districts such as Long Bien, Ha Dong, Nam Tu Liem, Bac Tu Liem, Tay Ho and Hoang Mai with quite high exceeding the national standard for planning public trees in urban areas many times. Particularly, Long Bien districts has the highest density of green trees in 12 districts up to 11 times, followed by Ha Dong (9 times), Nam Tu Liem (nearly 8 times), Bac Tu Liem over 7 times), Tay Ho (5 times) and Hoang Mai (nearly 4 times); meanwhile, urban centers such as Dong Da, Hai Ba Trung, Ba Dinh, Hoan Kiem and Thanh Xuan have low tree density, lower than standard. Specifically, Dong Da district has the lowest density of green trees in 12 urban districts about 4.8 times. Next to Hai Ba Trung districts more than 3 times. Hoan Kiem and Thanh Xuan are two times lower than the permitted standard. Cau Giay and Ba Dinh have the density of green trees approaching the standard level.

Acknowledgments: The authors would like to thank the People's Committee of Hanoi, Water Resources Institute for research funding and for providing key information for this study.

Author contributions: Constructing research ideas: H.K.V., T.T.H.; Select research method: H.K.V; Survey, sampling and analysis: Trang, T.H; Data processing: T.T.H; Writing-original draft preparation: H.K.V; Writing-review and editing: H.K.V.

Conflicts of Interest: The authors declare no conflict of interest.

\section{References}

1. Chang, Q.; Liu, X.W.; Wu J.S.; He, P. MSPA-based urban green infrastructure planning and management approach for urban sustainability: Case study of Longgang in China. $J$. Urban Plan. Dev. 2015, 141, 3.

2. Ossola, A.; Hopton, M.E. Measuring urban tree loss dynamics across residential landscapes. Sci. Total Environ. 2018, 612, 940-949, doi: 10.1016/j.scitotenv.2017.08.103.

3. $\mathrm{Pu}$, R.L.; Landry, S. A Comparative analysis of high spatial resolution IKONOS and WorldView-2 imagery for mapping urban tree species. Remote Sens. Environ. 2012, 124, 516-533.

4. Parmehr, E.G.; Amati, M. Estimation of urban tree canopy cover using random point sampling and remote sensing methods. Urban For. Urban Green. 2016, 20, 160-171.

5. Shojanoori, R.; Ismail, M.H.; Mansor, S.; Shafri, H. Generic rule-sets for automated detection of urban tree species from very high-resolution satellite data. Geocarto Int. 2018, 33, 1-36. 
VN J. Hydrometeorol. 2021, 7, 53-64; doi:10.36335/VNJHM.2021(7).53-64

6. Chance, C.M.; Coops, N.C.; Plowright, A.A.; Tooke, T.R.; Christen, A.; Aven, N. Invasive shrub mapping in an urban environment from hyperspectral and LiDAR-Derived attributes. Front. Plant Sci. 2016, 1-19. https://doi.org/10.3389/fpls.2016.01528

7. Nasi, R.; Eija, H.; Minna, B.; Paivi, L.S. Remote sensing of bark beetle damage in urban forests at individual tree level using a novel hyperspectral camera from UAV and aircraft. Urban For. Urban Green 2018, 30, 72-83. https://doi.org/10.1016/j.ufug.2018.01.010.

8. Harris, R.; Baumann, I. Open data policies and satellite Earth observation. Space Policy 2015, 32, 44-53. https://doi.org/1010.1016/j.spacepol.2015.01.001.

9. Zhu, Z.; Michael, A.W.; David, P.R.; Curtis, E.W.; Matthew, C.H.; Volker, C.R.; Sean P.H.; Crystal, S.; Patrick, H.; Peter, S.; Jean-Francois, P.; Leo, L.; Nima, P.; Ted, A.S. Benefits of the free and open Landsat data policy. Remote Sens. Environ. 2019, 224, 382 385.

10. https://hanoi.gov.vn/home

11. http://www.tnmtnd.hanoi.gov.vn/

12. https://Landsat.usgs.gov/Landsat8.php

13. https://www.usgs.gov

14. http://vietgis.com.vn/

15. Chi, P.K. New satellite generation - LDCM or Landsat 8, GeoViet. 2013.

16. Esau, I.; Miles, V.V.; Davy, R.; Miles, M.W.; Kurchatova, A. Victoria, V.M. Trends in normalize difference vegetation index (NDVI) associated with urban development in northern West Siberia. Atmos. Chem. Phys. 2016, 16, 9563-9577. https://doi.org/10.5194/acp-16-9563-2016.

17. Rumiana, V.; Monika, K. Mapping urban green spaces based on remote sensing data: Case studies in Bulgaria and Slovakia. Proceeding of the $6^{\text {th }}$ International Conference on Cartography and GIS. 2015.

18. Hanoi People's Committee. Land use planning up to 2020 and 5-year land use plan (20112015) for Hanoi districts.

19. Kham, D.V. et al. Building a model for forecasting rice yield and yield in the Red River Delta using Modis image data. 2011.

20. http://climatechangegis.blogspot.com/2012/03/cac-chi-so-thuc-vat-trong-vientham_4603.html

21. Hung, T.H.; Chi, P.K. Pilot study on application of remote sensing and GIS to manage urban green spaces and trees in Ha Tinh and Tra Vinh cities, 2011. 